It has something of the flavour of a nineteenth century scientific paper; one has the sense of the authors thinking out some of the contributory details as they write, instead of pretending throughout, as one is apt to do, that they have magisterially foreseen everything from the start. Their metallurgical achievement, experimentally simple but conceptually subtle, is quite sufficient for them to dispense with claims to omniscience.

\section{QUADRUPOLE COUPLINGS \\ Nitrogen Meusured}

from a Correspondent

Although nitrogen quadrupole couplings have been known for many years, a recent report by Blinc and his colleagues in Ljubljana (J. Chem. Phys., 57, 5087 ; 1972) demonstrates a new technique for their measurement and applies it to a number of bases such as uracil and amino-acids like cystine. When fully developed, the technique could mean much more sensitive measurements on solids. (Measurements on nitrogen-14 have always been difficult because of its small magnetic moment and the consequent weakness of the detected signals. In the 1950 s Dewar used to complain that he had difficulty distinguishing genuine signals from the effects of the underground trains below Queen Mary College, London.)

The importance of nitrogen in natural organic compounds needs no stressing. But whereas n.m.r. studies on protons and carbon- 13 signals are very informative, the existence of the quadrupole coupling with nitrogen-14 broadens all the resonance lines in solution and makes a simple n.m.r. experiment so unrewarding that most studies are based on the resonance of nitrogen-15, a sparse isotope with a spin of $1 / 2$ and no quadrupole moment which usually needs enrichment. But when the nitrogen-14 quadrupole coupling can be measured in solids the results are very sensitive to chemical structure and bonding.

The quadrupole couplings depend both on the distorted, non-spherical shape of the nucleus and on the electric field gradient, which reflects the spatial distribution of the valence electrons. Results are expressed in terms of a frequency parameter, $h^{-1} e q Q$, and an asymmetry parameter, $\eta$, which measures the lack of axial symmetry. The values of $h^{-1} e q Q$ range from 0 to $7 \mathrm{MHz}$ or higher, and typical of the chemical sensitivity are the values for the para diazine, pyrazine, which has $h^{-1} e q Q=4.857 \mathrm{MHz}$ and $\eta=0.536$; this differs considerably from the values for the meta compound, pyrimidine, where $h^{-1}$ eq $Q=4.436 \mathrm{MHz}$ and $\eta=$ 0.386 . These parameters are sensitive to environment and especially to hydro-

gen bonding. If the sensitivity of measurement can really be improved to the point where routine measurements are convenient, the importance for organic chemistry and biochemistry might be considerable.

The technique used by Blinc et al. is based on the double resonance schemes introduced by Hahn (Phys. Rev., 128, $2042 ; 1962$; and 166,$332 ; 1968)$. The sample spends some time in a magnetic field just large enough for the nitrogen14 resonance, with its quadrupole contribution, to be equal in frequency to that of the protons in the same field. A flip-flop relaxation process can then operate and affect the spin level populations in such a way that any unbalance of the nitrogen-14 populations is shared

\title{
Newfoundland Ophiolites and Plate Tectonics
}

IN next Monday's Nature Physical Science (February 5) the usefulness of ophiolites in unravelling pre-Mesozoic plate motions is again demonstrated, this time by Kennedy who deals with the Burlington Peninsula region of Newfoundland. The Appalachian system in Newfoundland comprises three major provinces (see diagram)-the Central Mobile Belt with its thick variably deformed late Precambrian volcanic and sedimentary rocks and, on each flank, stable platforms overlying similar rocks but which are thinner and less deformed. The Central Mobile Belt itself may then be divided threefold-an axial region which comprises chiefiy Ordovician and Silurian sedimentary and volcanic rocks which are moderately deformed and incipiently metamorphosed, and two marginal belts which comprise polydeformed metavolcanic and metasedimentary rocks of pre-Ordovician age containing major recumbent folds.

The area of particular interest to Kennedy is the northwestern part of the Central Mobile Belt which, with the Western Platform, has been interpreted as a late Precambrian-early Palaeozoic continental margin. Unfortunately, as Kennedy points out, all plate tectonic interpretations carried out so far suffer from being unable to explain the pre-Ordovician polydeformation in the western marginal crystalline belt, for the ophiolite sequences in this area have usually been regarded as Lower Ordovician and so their later displacement and transport cannot be related to the polydeformation.

From a reinterpretation of the structural relationships in the western marginal crystalline belt, Kennedy concludes that there are two ophiolite sequences of different ages; thus although one is undoubtedly Lower Ordovician, as previously thought, the with the protons. The sample then reaches a high magnetic field and the proton unbalance is examined with the high sensitivity appropriate to protons. Whether or not the nitrogen-14 populations are unbalanced depends on whether the frequency of a strong radiofrequency transmitter was or was not tuned to resonance with the quadrupole interval that is to be determined. Consequently a proton signal detector is sensitive to the nitrogen resonance.

The special importance of the particular scheme used by Blinc and his colleagues, however, is that the quadrupole resonance condition is met in zero magnetic field and so a powder or disordered solid is as useful as the single crystal required in other cases.

other is pre-Ordovician. The older sequence is structurally complex, apparently lacking the simple characteristic ophiolite structure, and is interpreted as the remains of a small ocean basin which closed and had its ophiolites obducted before the Ordovician. The polydeformation is then taken to reflect periodic movements in the closureobduction process. All this predates the formation of the second sequence of ophiolites which were presumably produced by later seafloor spreading and thrust up to their present position by later obduction. In this case no ocean basin closure was involved and so there was no transmission of stress through the adjacent rocks and hence no deformation.

In this way Kennedy is neatly able to solve a local problem. As he points out, however, the solution is really of more than local importance because "it provides the basis for relating some metamorphic nappe complexes in linear orogenic belts to plate movements".

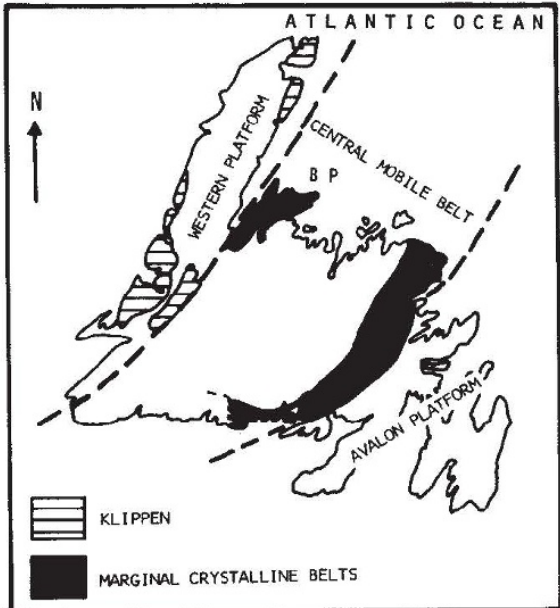

The tectonostratigraphic divisions of Newfoundland. BP, Burlington Peninsula. 